of a university and community hospital. Health Care Financial Review 1981;3:49-64.

3 Knaus WA, Draper EA, Wagner DP, Zimmerman JE, Birnbaum ML, Cullen DJ, et al. Evaluating outcome from intensive care: a preliminary multihospital comparison. Crit Care Med 1982;10:491-6.

4 Knaus WA, Draper EA, W/agner DP, Zimmerman JE. APACHE II: A severity of disease classification system. Crit Care Med 1985;13:818-29.

5 Knaus WA, Draper EA, Wagner DP, Zimmerman JE. An evaluation of outcome from intensive care in major medical centers. Ann Intern Med $1986 ; 104: 410-8$.

6 Marsh HM, Krishan I, Naessens JM, Strickland RA, Gracey DR, Campion $\mathrm{ME}$, et al. Assessment of prediction of mortality by using the APACHE II scoring system in intensive care units. Mayo Clin Proc 1990;65:1549-57.

7 Eagle KA, Mulley AG, Field TS, Skates S, Bero G, Clark CE, et al. Variation in intensive care unit practices in two community hospitals. Med Care 1991;29:1237-45.

8 French Multicentre Group of Intensive Care Unit Research and the INSERM Unit 169 of Statistical and Epidemiological Studies. Description of various types of intensive and intermediate care units in France. Intensive Care Medicine 1989;15:260-5.

9 Mahul P, Perrot D, Tempelhoff G, Gaussorgues P, Jospe R, Ducreux JC, et al. Short- and long-term prognosis, functional outcome following ICU for elderly. Intensive Care Medicine 1991;17:7-10.

10 Dragsted L, Jorgensen J, Jensen NH, Bonsing E, Jacobsen E, Knaus WA, al. Interhospital comparisons of patient outcome from intensive care: Importance of lead-time bias. Crit Care Med 1989;17:418-22.

11 Bion JF, Aitchison TC, Edlin SA, Ledingham IMcA. Sickness scoring and response to treatment as predictors of outcome from critical illness. Intensive Care Medicine 1988;14:167-72.

12 Chisakuta AM, Alexander JP. Audit in intensive care. The APACHE II classification of severity of disease. Ulster Med f 1990;59:161-7.

13 Gilbertson AA, Smith JM, Mostafa SM. The cost of an intensive care unit: a prospective study. Intensive Care Medicine 1991;17:204-8.

14 Marks RJ, Simons RS, Blizzard RA, Browne DRG. Predicting outcome in intensive therapy units-a comparison of APACHE II with subjective assessments. Intensive Care Medicine 1991;17:159-63.

15 Ridley S, Jackson R, Findlay J, Wallace P. Long term survival after intensive care. $B M \mathcal{F} 1990 ; 301: 1127-30$.

16 Shiell AM, Griffiths RD, Short AIK, Spiby J. An evaluation of the costs and outcome of adult intensive care in two units in the UK. Clinical Intensive Care 1990;1:256-61.

17 Waters $M$, Nightingale $P$, Edwards JD. A critical study of the APACHE scoring system using earlier data collection. Arch Emerg Med 1990;7:16-20.

18 Lemeshow S, Teres D, Pastides H, Spitz Avrunin J, Steingrub JS. A method for predicting survival and mortality of ICU patients using objectively derived weights. Crit Care Med 1985;13:519-25.

19 Lemeshow S, Teres D, Spitz Avrunin J, Gage RW. Refining intensive care unit outcome prediction by using changing probabilities of mortality. Crit Care Med 1988;16:470-7.

20 Teasdale G, Jennett B. Assessment of coma and impaired consciousness. A practical scale. Lancet 1974;11:81-4.

(Accepted 23 fuly 1993)
Department of Public

Health and Primary Care,

University of Oxford,

Gibson Laboratories

Building, Radcliffe

Infirmary, Oxford

OX2 6HE

K M Rowan, research fellow

M P Vessey, professor of

social and community medicine

Nuffield Department of

Anaesthetics, University of

Oxford, Radcliffe

Infirmary, Oxford

OX2 6HE

J H Kerr, consultant

anaesthetist

Intensive Therapy Unit, Morriston Hospital,

Swansea SA9 6NL

E Major, director

Health Promotion Sciences Unit, Department of Public Health and Policy, London School of Hygiene and Tropical Medicine, London WC1E 7HT $\mathrm{K}$ McPherson, professor of public health epidemiology

Intensive Care Unit, Broomfield Hospital, Chelmsford, Essex

CM1 5ET

A Short, director

Correspondence to:

Dr Rowan.

$B M \mp 1993 ; 307: 977-81$

\title{
Intensive Care Society's APACHE II study in Britain and Ireland-II: Outcome comparisons of intensive care units after adjustment for case mix by the American APACHE II method
}

\author{
K M Rowan, J H Kerr, E Major, K McPherson, A Short, M P Vessey
}

Abstract

Objectives-To compare outcome between intensive care units in Britain and Ireland both before and after adjustment for case mix with the American APACHE II method and to validate the American APACHE II method in Britain and Ireland.

Design-Prospective, cohort study of consecutive admissions to intensive care units.

Setting - 26 general intensive care units in Britain and Ireland.

Subjects -8796 admissions to the study intensive care units.

Main outcome measure-Death or survival at discharge from intensive care unit and hospital.

Results-At discharge from both intensive care unit and hospital there was a greater than twofold variation in crude mortality between the 26 units. After adjustment for case mix, variations in mortality were still apparent. For four intensive care units the observed numbers of deaths were significantly different from the number predicted by the American APACHE II equation. The overall goodness of fit, or predictive ability, of the APACHE II equation for the British and Irish data was good, being only slightly inferior to that obtained when the equation was tested on the data from which it had been derived. When patients were grouped by various factors such as age and diagnosis, the equation did not adjust across the subgroups in a uniform manner.

Conclusions-The American APACHE II equation did not fit the British and Irish data. Use of the American equation could be of advantage or disadvantage to individual intensive care units, depending on the mix of patients treated.

\section{Introduction}

Knaus et al described an equation to predict in-hospital mortality in critically ill patients in intensive care. ${ }^{1}$ Multiple logistic regression analyses of case mix and outcome data collected on 5030 patients admitted to intensive care units in the United States resulted in the development of the APACHE II equation. The equation described the relation of case mix, appropriately weighted, to hospital mortality. Case mix was defined by the patient's severity of illness (APACHE II score), surgical status (emergency surgical or elective surgical/non-surgical), and diagnosis (principal system or individual diagnostic category leading to admission to an intensive care unit).

One of the proposed uses of the APACHE II equation was to "prognostically stratify acutely ill patients" to "compare the efficacy of intensive care in different hospitals." The developers applied the equation to the database from which it was derived, both to test the predictive ability of the equation and to compare outcomes between intensive care units from 13 tertiary care hospitals in the United States. They calculated mortality ratios (observed hospital mortality divided by predicted hospital mortality) for each intensive care unit. One unit had significantly better results ( $41 \%$ fewer deaths than predicted) and one unit had significantly inferior results $(58 \%$ more deaths than predicted)..$^{23}$ They subsequently applied the American equation to intensive care units in two hospitals in New Zealand ${ }^{4}$ and more recently to units in six hospitals in Japan. ${ }^{5}$ In both studies they found that observed mortality did not differ significantly from that predicted by the American equation.

Mortality ratios estimated by the APACHE II equation have been used by other workers to audit their individual intensive care unit performance ${ }^{6-8}$ and to compare outcomes for surgical and non-surgical patients from four intensive care units in two hospitals. Two of these studies were undertaken in single, intensive care units in the United Kingdom. ${ }^{67}$

Inferences cannot be made from differences in mortality between British intensive care units with the American equation to adjust for case mix until the predictive ability of the equation (not only in terms of its overall goodness of fit to British data but also in terms of its ability to account for differences in mortality between subgroups) has been shown. We report the results of comparisons of outcome between 26 intensive care units in Britain and Ireland both before and after adjustment for case mix by the 
American APACHE II equation. We also report the overall fit and uniformity of fit of the equation for our data.

\section{Methods}

The study design, timing, methods of data collection, inclusion and exclusion criteria, and precise application of the APACHE II method for this study are described in the previous article. ${ }^{10}$ Data on outcome included the date and vital status of the patient at discharge from the intensive care unit and hospital. Mortality in an intensive care unit was measured as the proportion of patients dying within the unit. Mortality in hospital was measured as the overall proportion of patients dying in hospital, including those dying in the intensive care unit.

TABLE I-Mortality in 26 intensive care units and corresponding hospitals in Britain and Ireland

\begin{tabular}{lccccc}
\hline $\begin{array}{l}\text { Intensive care unit } \\
\text { (case No) }\end{array}$ & $\begin{array}{c}\text { No of } \\
\text { admissions }\end{array}$ & $\begin{array}{c}\text { No of deaths in } \\
\text { intensive care unit }\end{array}$ & $\begin{array}{c}\text { Mortality in } \\
\text { intensive care unit } \\
(\%)\end{array}$ & $\begin{array}{c}\text { No of deaths in } \\
\text { intensive care unit } \\
\text { and hospital }\end{array}$ & $\begin{array}{c}\text { Mortality in } \\
\text { hospital } \\
(\%)\end{array}$ \\
\hline 1 & 335 & 51 & $15 \cdot 2$ & 82 & $24 \cdot 5$ \\
2 & 412 & 129 & $31 \cdot 3$ & 188 & $45 \cdot 6$ \\
3 & 579 & 86 & $14 \cdot 9$ & 137 & $23 \cdot 7$ \\
4 & 522 & 85 & $16 \cdot 3$ & 121 & $23 \cdot 2$ \\
5 & 223 & 43 & $19 \cdot 3$ & 72 & $32 \cdot 3$ \\
6 & 159 & 29 & $18 \cdot 2$ & 42 & $26 \cdot 4$ \\
7 & 253 & 51 & $20 \cdot 2$ & 83 & $32 \cdot 8$ \\
8 & 282 & 36 & $12 \cdot 8$ & 59 & $20 \cdot 9$ \\
9 & 102 & 15 & $14 \cdot 7$ & 22 & $21 \cdot 6$ \\
10 & 214 & 63 & $29 \cdot 4$ & 96 & $44 \cdot 9$ \\
11 & 350 & 74 & $21 \cdot 1$ & 104 & $29 \cdot 7$ \\
12 & 388 & 79 & $20 \cdot 4$ & 106 & $27 \cdot 3$ \\
13 & 273 & 37 & $13 \cdot 6$ & 70 & $25 \cdot 6$ \\
14 & 170 & 38 & $22 \cdot 4$ & 65 & $32 \cdot 4$ \\
15 & 329 & 46 & $14 \cdot 0$ & 71 & $20 \cdot 1$ \\
16 & 251 & 36 & $14 \cdot 3$ & 75 & $31 \cdot 7$ \\
17 & 237 & 54 & $22 \cdot 8$ & 63 & $33 \cdot 7$ \\
18 & 187 & 50 & $26 \cdot 7$ & 39 & $29 \cdot 6$ \\
19 & 132 & 25 & $18 \cdot 9$ & 103 & $22 \cdot 4$ \\
20 & 460 & 63 & $13 \cdot 7$ & 52 & $23 \cdot 5$ \\
21 & 221 & 39 & $17 \cdot 7$ & 128 & $34 \cdot 1$ \\
22 & 375 & 102 & $27 \cdot 2$ & 139 & $28 \cdot 3$ \\
23 & 492 & 95 & $19 \cdot 3$ & 145 & $24 \cdot 3$ \\
24 & 598 & 96 & $16 \cdot 1$ & 137 & $29 \cdot 8$ \\
25 & 460 & 62 & $11 \cdot 2$ & 178 & $22 \cdot 5$ \\
26 & 792 & 89 & $17 \cdot 9$ & 2433 & $27 \cdot 7$ \\
\hline Total & 8796 & 1573 & & & \\
\hline
\end{tabular}

For mortality in intensive care unit $\chi^{2}=172 \cdot 2, \mathrm{df}=25, \mathrm{p}<0.0001$. For mortality in hospital $\chi^{2}=173.5$, df $=25$, $\mathrm{p}<0.0001$.

TABLE II-Mortality ratios in 26 intensive care units and corresponding hospitals after adjustment for case mix by American APACHE II equation

\begin{tabular}{|c|c|c|c|c|}
\hline \multirow{2}{*}{$\begin{array}{l}\text { Intensive care unit } \\
\text { (case No) }\end{array}$} & \multirow{2}{*}{$\begin{array}{c}\text { No of } \\
\text { admissions }\end{array}$} & \multicolumn{2}{|c|}{$\begin{array}{l}\text { No of deaths in intensive care unit and hospital } \\
\text { (mortality (\%)) }\end{array}$} & \multirow{2}{*}{$\begin{array}{c}\text { Mortality ratio } \dagger \\
\text { (95\% confidence interval) }\end{array}$} \\
\hline & & Observed & Predicted & \\
\hline 1 & 335 & $82(24 \cdot 5)$ & $117.5(35 \cdot 1)$ & $0.70(0.56 \text { to } 0.87)^{\star \star}$ \\
\hline 2 & 412 & $188(45 \cdot 6)$ & $169 \cdot 1(41 \cdot 0)$ & $1.11(0.96$ to 1.28$)$ \\
\hline 3 & 579 & $137(23 \cdot 7)$ & $165 \cdot 4(28 \cdot 6)$ & $0.83(0.70 \text { to } 0.98)^{\star}$ \\
\hline 4 & 522 & $121(23 \cdot 2)$ & $146 \cdot 2(28 \cdot 0)$ & $0.83(0.69 \text { to } 0.99)^{\star}$ \\
\hline 5 & 223 & $72(32 \cdot 3)$ & $59 \cdot 7(26 \cdot 8)$ & $1.21(0.94$ to 1.52$)$ \\
\hline 6 & 159 & $42(26 \cdot 4)$ & $37.5(23.6)$ & $1.12(0.81$ to 1.51$)$ \\
\hline 7 & 253 & $83(32 \cdot 8)$ & $78 \cdot 7(31 \cdot 1)$ & $1.05(0.84$ to 1.31$)$ \\
\hline 8 & 282 & $59(20 \cdot 9)$ & $72.7(25 \cdot 8)$ & $0.81(0.62$ to 1.05$)$ \\
\hline 9 & 102 & $22(21 \cdot 6)$ & $30.0(29 \cdot 4)$ & $0.73(0.46$ to 1.11$)$ \\
\hline 10 & 214 & $96(44 \cdot 9)$ & $69 \cdot 1(32 \cdot 3)$ & $1.39(1.13 \text { to } 1.70)^{\star \star}$ \\
\hline 11 & 350 & $104(29 \cdot 7)$ & $103 \cdot 1(29 \cdot 5)$ & $1.01(0.82$ to 1.22$)$ \\
\hline 12 & 388 & $106(27 \cdot 3)$ & $91 \cdot 1(23.5)$ & $1.16(0.95$ to 1.41$)$ \\
\hline 13 & 273 & $70(25 \cdot 6)$ & $60 \cdot 4(22 \cdot 1)$ & $1.16(0.90$ to 1.46$)$ \\
\hline 14 & 170 & $55(32 \cdot 4)$ & $56.2(33.0)$ & $0.98(0.74$ to 1.27$)$ \\
\hline 15 & 329 & $66(20 \cdot 1)$ & $62.9(19 \cdot 1)$ & $1.05(0.81$ to 1.33$)$ \\
\hline 16 & 251 & $71(28 \cdot 3)$ & $63 \cdot 4(25 \cdot 2)$ & $1.12(0.87$ to 1.41$)$ \\
\hline 17 & 237 & $75(31 \cdot 7)$ & $70 \cdot 1(29 \cdot 6)$ & $1.07(0.84$ to 1.34$)$ \\
\hline 18 & 187 & $63(33 \cdot 7)$ & $64 \cdot 4(34 \cdot 4)$ & $0.98(0.75$ to 1.25$)$ \\
\hline 19 & 132 & $39(29 \cdot 6)$ & $33.8(25 \cdot 6)$ & $1.15(0.82$ to 1.58$)$ \\
\hline 20 & 460 & $103(22 \cdot 4)$ & $101 \cdot 1(22 \cdot 0)$ & $1.02(0.83$ to 1.24$)$ \\
\hline 21 & 221 & $52(23 \cdot 5)$ & $61 \cdot 1(27 \cdot 6)$ & $0.85(0.64$ to 1.12$)$ \\
\hline 22 & 375 & $128(34 \cdot 1)$ & $110 \cdot 3(29 \cdot 4)$ & $1.16(0.97$ to 1.38$)$ \\
\hline 23 & 492 & $139(28.3)$ & $118 \cdot 2(24.0)$ & $1.18(0.99$ to 1.39$)$ \\
\hline 24 & 598 & $145(24 \cdot 3)$ & $137 \cdot 9(23 \cdot 1)$ & $1.05(0.89$ to 1.24$)$ \\
\hline 25 & 460 & $137(29 \cdot 8)$ & $133.0(28.9)$ & $1.03(0.86$ to 1.22$)$ \\
\hline 26 & 792 & $178(22 \cdot 5)$ & $178 \cdot 2(22 \cdot 5)$ & $1.00(0.86$ to 1.16$)$ \\
\hline Total & 8796 & $2433(27 \cdot 7)$ & $2390(27 \cdot 2)$ & $1.02(0.98$ to 1.06$)$ \\
\hline
\end{tabular}

tObserved number of deaths divided by predicted number. $\star$ Significant at $5 \%$ level.
Applying the American APACHE II equation, we estimated a predicted risk of dying in hospital for each patient in our database (see appendix). ${ }^{1}$ When a patient had a diagnosis that was not represented in the American equation the system diagnostic category coefficient was applied. Summing of individual patient risks yielded a predicted number of deaths for groups of patients. The observed number of deaths within groups was compared with the predicted number of deaths and a mortality ratio (number of observed deaths divided by number of deaths predicted by APACHE II) calculated. Ninety five per cent confidence intervals were calculated for each mortality ratio. ${ }^{11}$ Differences between observed and predicted numbers of deaths were tested with the simple continuity corrected $\chi^{2}$ statistic.

No single standard measure has been used to describe the overall goodness of fit or predictive ability of multiple logistic regression equations. We used four different methods: calibration curves, classification tables, analysis of receiver operating characteristic curves, ${ }^{12}$ and a $\chi^{2}$ statistic proposed by Lemeshow and Hosmer. ${ }^{13}$ These are described in the appendix.

\section{Results}

In addition to the patients already excluded from our database,${ }^{10}$ a further $276(2 \cdot 4 \%)$ patients who had had coronary artery bypass grafting and $27(0.2 \%)$ patients with burns were removed as the APACHE II equation was not proposed for use in these two groups. This left a database of 8796 patients, with a mean number of patients per intensive care unit of 338 and a range between units of 102 to 792 patients (table I).

COMPARISONS OF OUTCOME BEFORE AND AFTER ADJUSTMENT FOR CASE MIX

The overall proportion of patients dying in the intensive care unit was $17 \cdot 9 \%$. Mortality in the intensive care unit varied $2 \cdot 8$-fold between the 26 units from $11.2 \%$ in unit 26 to $31.3 \%$ in unit 2 (table I). The overall proportion of patients dying in hospital was $27 \cdot 7 \%$, varying $2 \cdot 3$-fold, from $20 \cdot 1 \%$ in unit 15 to $45.6 \%$ in unit 2 .

The mortality ratios (observed divided by predicted deaths) for the units ranged from 0.70 in unit 1 to 1.39 in unit 10 (table II). For four units $(1,3,4$, and 10 ), the observed numbers of deaths were significantly different from the numbers predicted by the APACHE II equation ( 3 and $4, p<0.05 ; 1$ and $10, p<0.01$ ).

\section{VALIDATION OF THE APACHE II EQUATION}

Overall goodness of fit

The calibration curve for the APACHE II equation applied to our data is shown in figure 1 . This showed that as the predicted risk of dying in hospital increased ( $x$ axis) the proportion of patients who died also increased ( $y$ axis, right hand side). The observed mortality for two of the predicted risk groups (15-20\% and $30-35 \%$ ), however, lay significantly above the diagonal line (which represents the relation where observed and predicted deaths are equal). In contrast, for four predicted risk groups $(75-80 \%$ and above $85 \%$ ) the observed mortality fell significantly below the diagonal line.

Table III shows the classification tables. With a decision criterion of $10 \%$ the proportion of the observed deaths predicted by the model was high $(93.7 \%)$. This result was, however, associated with a high false positive rate, with $54.9 \%$ of survivors predicted to die. At the other extreme with a decision criterion of $90 \%$ only $7 \cdot 4 \%$ of the observed deaths were predicted, but this was associated with a low false positive rate $(0 \cdot 6 \%)$. When decision criteria were applied at 5\% intervals from $5 \%$ to $95 \%$ the highest overall proportion correctly 


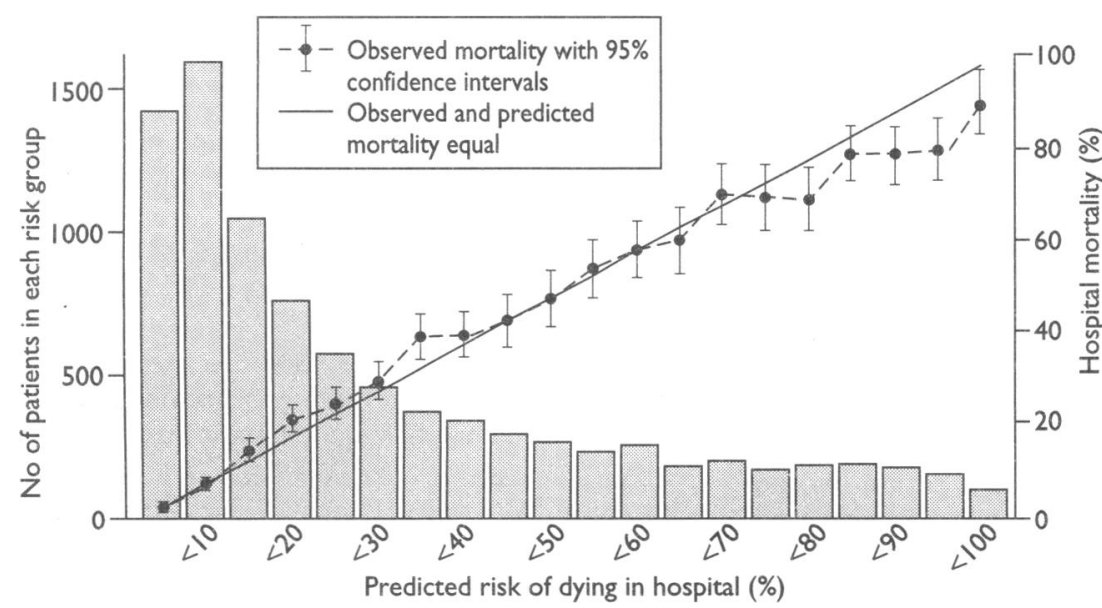

FIG 1-Observed proportion of patients dying in hospital in Britain and Ireland according to their predicted risk of dying estimated by American APACHE II equation. Line of perfect predictive ability, when observed and predicted mortality are equal, is given to show overall goodness of fit of the equation

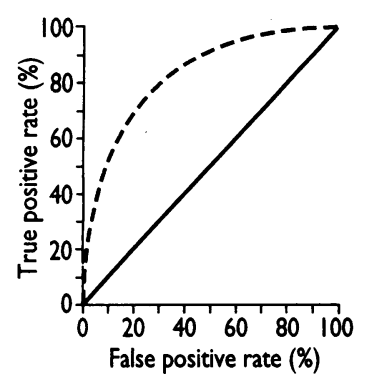

TABLE III-Classification tables for American APACHE II equation applied to data from British and Irish intensive care units and corresponding hospitals

\begin{tabular}{|c|c|c|c|}
\hline & No predicted to live & No predicted & Total \\
\hline \multicolumn{4}{|c|}{ Decision criterion of $10 \%$} \\
\hline $\begin{array}{l}\text { No of observed survivors } \\
\text { No of observed dead } \\
\text { Total }\end{array}$ & $\begin{array}{r}2867 \\
153 \\
3020\end{array}$ & $\begin{array}{l}3496 \\
2280 \\
5776\end{array}$ & $\begin{array}{l}6363 \\
2433 \\
8796\end{array}$ \\
\hline
\end{tabular}

True positive rate ( $95 \%$ confidence interval) (\%) 93.7 ( $92 \cdot 7$ to $94 \cdot 7)$

True positive rate (95\% confidence interval) $(\%) 93.7(92 \cdot 7$ to $94 \cdot 7)$

Overall correctclassification ( $95 \%$ confidence interval) $(\%) 58 \cdot 5(57 \cdot 5$ to $59 \cdot 5)$.

False positive rate $(\%)$

FIG 2-Receiver operating

characteristic curves showing predictive ability of American APACHE II equation applied todata from Britain and Ireland

$\begin{array}{lcrl} & & \\ \text { No of observed survivors } & 5824 & 539 & 6363 \\ \text { No of observed dead } & 1261 & 1172 & 2433 \\ \text { Total } & 7085 & 1711 & 8796\end{array}$

True positive rate ( $95 \%$ confidence interval) (\%) $48 \cdot 2$ (46.2 to 50.2).

False positive rate $(95 \%$ confidence interval) (\%) 8.5 ( 7.8 to $9 \cdot 2)$.

Overall correct classification ( $95 \%$ confidence interval) (\%) $79 \cdot 5(78 \cdot 7$ to $80 \cdot 3)$

$$
\text { Decision criterion of } 90 \%
$$

$\begin{array}{lrrr}\text { No of observed survivors } & 6327 & 36 & 6363 \\ \text { No of observed dead } & 2252 & 181 & 2433 \\ \text { Total } & 8579 & 217 & 8796\end{array}$

True positive rate ( $95 \%$ confidence interval) (\%) $7 \cdot 4(6 \cdot 4$ to $8 \cdot 4)$. False positive rate $(95 \%$ confidence interval) $(\%) 0.6(0.4$ to 0.8$)$ Overall correct classification ( $95 \%$ confidence interval) (\%) 74.0 (73.1 to 74.9 ).

TABLE IV-Goodness of fit of American APACHE II equation for data from Britain and Ireland by Lemeshow-Hosmer $\chi^{2}$ statistic

\begin{tabular}{|c|c|c|c|c|c|}
\hline \multirow{2}{*}{$\begin{array}{l}\text { Predicted risk } \\
\text { of dying in } \\
\text { hospital (\%) }\end{array}$} & \multirow{2}{*}{$\begin{array}{l}\text { No } \\
\text { of } \\
\text { cases }\end{array}$} & \multicolumn{2}{|c|}{ No of deaths } & \multicolumn{2}{|c|}{ No of survivors } \\
\hline & & Observed & Expected & Observed & Expected \\
\hline $0-$ & 3020 & 153 & $157 \cdot 40$ & 2867 & $2862 \cdot 60$ \\
\hline $10-$ & 1797 & 313 & 260.64 & 1484 & 1536.3 \\
\hline $20-$ & 1021 & 274 & 252.04 & 747 & 768.96 \\
\hline $30-$ & 699 & 275 & 243.97 & 424 & 455.0 \\
\hline $40-$ & 548 & 246 & $247 \cdot 46$ & 302 & 300.54 \\
\hline $50-$ & 464 & 260 & $255 \cdot 42$ & 204 & 208.5 \\
\hline $60-$ & 358 & 234 & 232.94 & 124 & 125.06 \\
\hline $70-$ & 333 & 230 & $249 \cdot 31$ & 103 & 83.69 \\
\hline $80-$ & 339 & 267 & $287 \cdot 85$ & 72 & $51 \cdot 15$ \\
\hline $90-100$ & 217 & 181 & 203.90 & 36 & $13 \cdot 10$ \\
\hline
\end{tabular}

Sum of $\chi^{2}=79 \cdot 81, \mathrm{df}=8$.

TABLE V-Mortality ratios by age group for patients in 26 intensive care units after adjustment for case mix by American APACHE II equation

\begin{tabular}{|c|c|c|c|c|}
\hline \multirow[b]{2}{*}{ Age group (years) } & \multirow{2}{*}{$\begin{array}{c}\text { No of } \\
\text { admissions }\end{array}$} & \multicolumn{2}{|c|}{$\begin{array}{l}\text { No of deaths in intensive care unit and hospital } \\
\text { (mortality (\%)) }\end{array}$} & \multirow{2}{*}{$\begin{array}{c}\text { Mortality ratio } \dagger \\
\text { (95\% confidence interval) }\end{array}$} \\
\hline & & Observed & Predicted & \\
\hline $16-25$ & 887 & $103(11 \cdot 6)$ & $117 \cdot 2(13 \cdot 2)$ & $0.88(0.72$ to 1.07$)$ \\
\hline $26-35$ & 776 & $102(13 \cdot 1)$ & $119.9(15.4)$ & $0.85(0.69$ to 1.03$)$ \\
\hline $36-45$ & 777 & $164(21 \cdot 1)$ & $156.0(20 \cdot 1)$ & $1.05(0.90$ to 1.22$)$ \\
\hline $46-55$ & 950 & $244(25 \cdot 7)$ & $250.0(26 \cdot 3)$ & $0.98(0.86$ to 1.11$)$ \\
\hline $56-65$ & 1887 & $535(28.4)$ & $549 \cdot 4(29 \cdot 1)$ & $0.97(0.89$ to 1.06$)$ \\
\hline $66-75$ & 2344 & $803(34 \cdot 3)$ & $787 \cdot 7(33 \cdot 6)$ & $1.02(0.95$ to 1.09$)$ \\
\hline $76-85$ & 1071 & $429(40 \cdot 1)$ & $373.4(34.9)$ & $1.15(1.04 \text { to } 1.26)^{\star \star}$ \\
\hline$\geqslant 86$ & 104 & $53(51 \cdot 0)$ & $37 \cdot 1(35 \cdot 7)$ & $1.43(1.07 \text { to } 1.87)^{\star}$ \\
\hline
\end{tabular}

tObserved number of deaths divided by predicted number.

${ }^{\star}$ Significant at $5 \%$ level. classified (predicted survivors who survive plus predicted non-survivors who die) was $79 \cdot 5 \%$ with a $50 \%$ decision criterion, with a true positive rate of $48.2 \%$ and a false positive rate of $8.5 \%$.

Figure 2 shows the receiver operating characteristic curve for the APACHE II equation applied to our data. The area under the curve was $0 \cdot 83$. Table IV presents the data for calculation of the Lemeshow-Hosmer statistic. The significant departure from the null hypothesis, measured by the Lemeshow-Hosmer $\chi^{2}$ statistic for our data, does not necessarily imply a bad fit, just that its imperfections are of such a size that they can be detected in this large sample size.

\section{Uniformity of fit}

Observed hospital mortality was similar to that predicted by the APACHE II equation for patients grouped by age up to 75 years (table V). For patients 76 years and older the observed numbers of deaths were greater than those predicted. Patients without any of the chronic health conditions defined in APACHE II had a slightly raised significant mortality ratio of $1.05(p<0.05)$. This was, however, in a large group of 6814 patients.

The number of deaths predicted by the APACHE II equation was similar to the number observed for both surgical and non-surgical patients (table VI). The independent variable in the APACHE II equation reflecting surgical status is whether the patient has had emergency surgery or not. The observed and predicted number of deaths was similar for the two groups.

When patients were grouped by diagnosis (principal system diagnostic category leading to admission to an intensive care unit) by the American diagnostic categories of the APACHE II method the mortality ratios were significantly raised for surgical patients with diagnoses pertaining to the cardiovascular system and for both surgical and non-surgical patients with diagnoses pertaining to the neurological system. In contrast, the mortality ratio was significantly lowered for surgical patients with respiratory disease (table VI).

For patients grouped by the acute physiology score of the APACHE II score the observed number of deaths was similar to the predicted number for all groups. When patients were grouped by APACHE II score, however, the predicted number of deaths was significantly greater than the number observed for the two lowest score bands. The opposite was true for the patients with scores between 20 and 24, when the observed number of deaths was significantly greater than the number predicted (table VII).

\section{Discussion}

When measuring the outcome of intensive care as crude mortality in intensive care units we found a large variation between the units. Some of this variation might, however, reflect different discharge practices between the units such that a patient who would remain and die within a unit in one hospital may be discharged and die on the ward in another. Differences in discharge practices can result from such factors as pressure for intensive care beds or variations in units' discharge policies. The observed decrease in variation between the units for crude hospital mortality relative to intensive care unit mortality suggests these biases might exist. Whereas the ultimate outcome may be best measured at some point after hospital discharge, mortality in hospital rather than the intensive care unit may be more sensitive to true variation.

Examination of differences in case mix between units may further inform the variations which remain between hospital mortality. Indeed, in 22 of the 26 units studied adjustment for case mix by the APACHE II method explained the observed differences 
in crude hospital mortality. Before the results with such a tool can be accepted, however, the tool must be rigorously validated, especially when it was originally developed within another medical culture. Validation must include testing not only the overall goodness of fit but also the uniformity of fit of the equation for our data.

In the absence of a single, agreed method to measure overall goodness of fit we used four different methods. The overall goodness of fit of the American equation for the British and Irish data was good with each method and it was only slightly inferior to the goodness of fit obtained by the developers of APACHE II. ${ }^{1}$

On investigation of the uniformity of fit of the American APACHE II equation for our data, we found that when patients were grouped by characteristics, such as age and diagnosis, the equation did not adjust across the subgroups uniformly. This lack of uniformity of fit is illustrated by underprediction of deaths for patients 76 years or older, which has also been reported by other groups, ${ }^{14} 15$ and by overprediction of deaths for patients with, for example, a respiratory condition treated surgically.

Potential factors that could give rise to the lack of uniformity of fit of the American equation for our data are: (a) systematic differences in medical definitions and diagnostic labelling between the two countries $^{16} ;(b)$ true differences in the diagnostic mix between the countries; $(c)$ systematic differences in

TABLE VI-Mortality ratios by surgical status and system diagnostic category for patients in 26 intensive care units after adjustment for case mix by American APACHE II equation

\begin{tabular}{|c|c|c|c|c|}
\hline \multirow{2}{*}{$\begin{array}{l}\text { System } \\
\text { diagnostic category }\end{array}$} & \multirow{2}{*}{$\begin{array}{c}\text { No of } \\
\text { admissions }\end{array}$} & \multicolumn{2}{|c|}{$\begin{array}{l}\text { No of deaths in intensive care unit and hospital } \\
(\text { mortality }(\%))\end{array}$} & \multirow{2}{*}{$\begin{array}{c}\text { Mortality ratio } t \\
\text { (95\% confidence interval) }\end{array}$} \\
\hline & & Observed & Predicted & \\
\hline \multicolumn{5}{|c|}{ Surgical } \\
\hline $\begin{array}{l}\text { Cardiovascular } \\
\text { Gastrointestinal } \\
\text { Neurological } \\
\text { Respiratory } \\
\text { Renal } \\
\text { Haematological } \\
\text { Metabolic } \\
\text { Total }\end{array}$ & $\begin{array}{r}2182 \\
1286 \\
180 \\
1030 \\
211 \\
13 \\
13 \\
4907\end{array}$ & $\begin{array}{r}441(20 \cdot 2) \\
354(27 \cdot 5) \\
45(25 \cdot 0) \\
109(10 \cdot 6) \\
27(12 \cdot 8) \\
2(40 \cdot 0) \\
2(15 \cdot 4) \\
980(20 \cdot 0)\end{array}$ & $\begin{array}{r}375 \cdot 4(17 \cdot 2) \\
375 \cdot 1(29 \cdot 2) \\
28 \cdot 7(15 \cdot 9) \\
178 \cdot 6(17 \cdot 3) \\
31 \cdot 5(14 \cdot 9) \\
1 \cdot 6(32 \cdot 0) \\
2 \cdot 1(16 \cdot 2) \\
993 \cdot 0(20 \cdot 2)\end{array}$ & $\begin{array}{l}1.17(1.07 \text { to } 1.29)^{\star \star} \\
0.94(0.85 \text { to } 1.05) \\
1.57(1.14 \text { to } 2.10)^{\star \star} \\
0.61(0.50 \text { to } 0.74)^{\star \star} \\
0.86(0.56 \text { to } 1.25) \\
1.25(0.15 \text { to } 4.52) \\
0.95(0.12 \text { to } 3.44) \\
0.99(0.93 \text { to } 1.05)\end{array}$ \\
\hline \multicolumn{5}{|c|}{ Non-surgical } \\
\hline $\begin{array}{l}\text { Cardiovascular } \\
\text { Gastrointestinal } \\
\text { Neurological } \\
\text { Respiratory } \\
\text { Renal } \\
\text { Haematological } \\
\text { Metabolic } \\
\text { Total }\end{array}$ & $\begin{array}{r}1489 \\
217 \\
844 \\
1200 \\
46 \\
25 \\
68 \\
3889\end{array}$ & $\begin{array}{r}643(43 \cdot 2) \\
125(57 \cdot 6) \\
225(26 \cdot 7) \\
424(35 \cdot 3) \\
17(37 \cdot 0) \\
11(44 \cdot 0) \\
8(11 \cdot 8) \\
1453(37 \cdot 4)\end{array}$ & $\begin{array}{r}668 \cdot 6(44.9) \\
122 \cdot 8(56 \cdot 6) \\
150 \cdot 6(17.8) \\
418 \cdot 7(34.9) \\
15.5(33 \cdot 7) \\
6.9(27.6) \\
15.0(22 \cdot 0) \\
1398 \cdot 1(35.9)\end{array}$ & $\begin{array}{l}0.96(0.89 \text { to } 1.04) \\
1.02(0.85 \text { to } 1.21) \\
1.49(1.31 \text { to } 1.70)^{\star \star} \\
1.01(0.92 \text { to } 1.11) \\
1.10(0.64 \text { to } 1.76) \\
1.59(0.80 \text { to } 2.85) \\
0.53(0.23 \text { to } 1.05) \\
1.04(0.99 \text { to } 1.09)\end{array}$ \\
\hline
\end{tabular}

†Observed number of deaths divided by predicted number.

$\star \star$ Significant at $1 \%$ level.

TABLE VII-Mortality ratios by acute physiology and APACHE II scores for patients in 26 intensive care units after adjustment for case mix by American APACHE II equation

\begin{tabular}{|c|c|c|c|c|}
\hline & \multirow{2}{*}{$\begin{array}{c}\text { No of } \\
\text { admissions }\end{array}$} & \multicolumn{2}{|c|}{$\begin{array}{l}\text { No of deaths in intensive care unit and hospital } \\
\text { (mortality (\%)) }\end{array}$} & \multirow{2}{*}{$\begin{array}{c}\text { Mortality ratio } \dagger \\
\text { (95\% confidence interval) }\end{array}$} \\
\hline & & Observed & Predicted & \\
\hline \multicolumn{5}{|c|}{ Acute physiology score: } \\
\hline $0-4$ & 563 & $32(5 \cdot 7)$ & $28 \cdot 0(5 \cdot 0)$ & $1.14(0.78$ to 1.61$)$ \\
\hline $5-9$ & 2189 & $192(8 \cdot 8)$ & $218 \cdot 4(10 \cdot 0)$ & $0.88(0.76$ to 1.01$)$ \\
\hline $10-14$ & 2600 & $482(18 \cdot 5)$ & $484 \cdot 9(18 \cdot 7)$ & $0.99(0.91$ to 1.09$)$ \\
\hline $15-19$ & 1585 & $552(34 \cdot 8)$ & $510 \cdot 5(32 \cdot 2)$ & $1.08(0.99$ to 1.18$)$ \\
\hline $20-24$ & 881 & $463(52 \cdot 6)$ & $434 \cdot 8(49 \cdot 4)$ & $1.06(0.97$ to 1.17$)$ \\
\hline $25-29$ & 555 & $383(69 \cdot 0)$ & $362 \cdot 0(65 \cdot 2)$ & $1.07(0.95$ to 1.17$)$ \\
\hline $30-34$ & 247 & $178(72 \cdot 1)$ & $193.8(78.5)$ & $0.92(0.79$ to 1.06$)$ \\
\hline$\geqslant 35$ & 176 & $151(85.8)$ & $158 \cdot 6(90 \cdot 1)$ & $0.95(0.81$ to 1.12$)$ \\
\hline \multicolumn{5}{|c|}{ APACHE II score: } \\
\hline $0-4$ & 275 & $1(0 \cdot 4)$ & $7 \cdot 3(2 \cdot 7)$ & $0.14(0.0 \text { to } 0.76)^{\star}$ \\
\hline $5-9$ & 1048 & $43(4 \cdot 1)$ & $59 \cdot 7(5 \cdot 7)$ & $0.72(0.52 \text { to } 0.97)^{\star}$ \\
\hline $10-14$ & 2064 & $210(10 \cdot 2)$ & $217 \cdot 5(10 \cdot 5)$ & $0.97(0.84$ to 1.11$)$ \\
\hline $15-19$ & 2079 & $395(19 \cdot 0)$ & $395 \cdot 7(19 \cdot 0)$ & $1.00(0.90$ to 1.10$)$ \\
\hline $20-24$ & 1492 & $568(38 \cdot 1)$ & $510 \cdot 3(34 \cdot 2)$ & $1.11(1.02 \text { to } 1.21)^{\star}$ \\
\hline $25-29$ & 878 & $499(56.8)$ & $457.9(52.2)$ & $1.09(1.00$ to 1.19$)$ \\
\hline $30-34$ & 507 & $353(69 \cdot 6)$ & $349 \cdot 8(69 \cdot 0)$ & $1.01(0.91$ to 1.12$)$ \\
\hline$\geqslant 35$ & 453 & $364(80 \cdot 4)$ & $392 \cdot 8(86.7)$ & $0.93(0.83$ to 1.03$)$ \\
\hline
\end{tabular}

†Observed number of deaths divided by predicted number.

«Significant at $5 \%$ level.

\section{Clinical implications}

- Crude death rates in hospital vary more than twofold between intensive care units in Britain and Ireland

- In this study the American APACHE II equation was used to adjust for the differences in the case mix of patients

- The outcome in four intensive care units remained significantly different from that expected even after adjustment for case mix

- Although the overall goodness of fit of the American APACHE II equation for British and Irish data is satisfactory, the equation does not fit the data uniformly

- Before the American APACHE II equation can be widely adopted the uniformity of fit needs to be improved for British and Irish patients

the measurement of physiological variables between the countries; $(d)$ systematic differences in the effectiveness of treatment; and $(e)$ the possibility that differences exist in the age specific health status between the countries.

Our results show that before an existing case mix measure is applied, especially those developed in other countries, it must first be rigorously validated. This is true not only for intensive care but for all areas of health care. If the case mix measure used does not fit the data to which it is applied the wrong conclusions may be drawn from the results. In addition, some measures of case mix may produce good overall goodness of fit but may still not fit uniformly, as we found with the American APACHE II equation. We will consider in a subsequent paper whether an APACHE II equation derived from British data would provide better case mix adjustment than the existing American equation.

This study was supported by grants from the Medical Research Council, the King's Fund for Health Services Development, the Intensive Care Society, and the Medical Research Fund. We acknowledge the directors and staff of the participating intensive care units for collecting the data: Bristol Royal Infirmary; Broomfield Hospital, Chelmsford; Freeman Hospital, Newcastle; Glasgow Royal Infirmary; Lewisham Hospital; Morriston Hospital, Swansea; Royal Devon and Exeter Hospital; Western Infirmary, Glasgow; University Hospital of South Manchester; Dudley Road Hospital, Birmingham; Northampton General Hospital; Broadgreen Hospital, Liverpool; John Radcliffe Hospital, Oxford; Sunderland District General Hospital; Salisbury General Hospital; Victoria Infirmary, Glasgow; Western General Hospital, Edinburgh; Beaumont Hospital, Dublin; Royal Cornwall Hospital, Truro; University College Hospital, London; East Glamorgan Hospital; Royal Sussex County Hospital, Brighton; Princess Margaret Hospital, Swindon; Newcastle General Hospital; Countess of Chester Hospital; and Royal Infirmary of Edinburgh.

\section{Appendix}

PREDICTING RISK OF DYING IN HOSPITAL

Table VIII shows the weighting for the diagnostic categories according to surgical status in the American APACHE II equation. The predicted risk of dying in hospital was calculated from the equation $\ln (\mathrm{P} / 1-\mathrm{P})=-3.517+0.146 x$ APACHE II score +0.603 if after emergency surgery + weight of diagnostic category, where $P$ is the predicted risk of dying in hospital.

METHODS FOR TESTING OVERALL GOODNESS OF FIT

Calibration curves display observed hospital mortality in patients grouped by predicted risk of dying in hospital. Patients were divided into groups on the basis of their 
TABLE VII-Coefficients for diagnostic categories according to surgical status with American APACHE II equation

\begin{tabular}{|c|c|c|c|}
\hline Surgical & Coefficient & Non-surgical & Coefficient \\
\hline $\begin{array}{l}\text { Cardiovascular } \\
\text { Multiple trauma } \\
\text { Heart valve surgery } \\
\text { Peripheral vascular surgery } \\
\text { Haemorrhagic shock } \\
\text { Chronic cardiovascular disease } \\
\text { Gastrointestinal } \\
\text { Neoplasm } \\
\text { Bleeding } \\
\text { Perforation or obstruction } \\
\text { Haematological } \\
\text { Renal } \\
\text { Neoplasm } \\
\text { Transplant } \\
\text { Metabolic } \\
\text { Neurological } \\
\text { Craniotomy for neoplasm } \\
\text { Head trauma } \\
\text { Craniotomy for intracerebral, subdural, } \\
\text { or subarachnoid haemorrhage } \\
\text { Respiratory } \\
\text { Thoracic surgery for neoplasm } \\
\text { Respiratory insufficiency after surgery }\end{array}$ & $\begin{array}{r}-0.797 \\
-1.684 \\
-1.261 \\
-1.315 \\
-0.682 \\
-1.376 \\
-0.613 \\
-0.248 \\
-0.617 \\
0.060 \\
-0.196 \\
-0.196 \\
-1.204 \\
-1.042 \\
-0.196 \\
-1.150 \\
-1.245 \\
-0.955 \\
-0.788 \\
-0.610 \\
-0.802 \\
-0.140\end{array}$ & $\begin{array}{l}\text { Cardiovascular } \\
\text { Multiple trauma } \\
\text { Coronary artery disease } \\
\text { Thoracic or abdominal aneurysm } \\
\text { Congestive heart failure } \\
\text { Hypertension } \\
\text { Rhythm disturbance } \\
\text { Cardiogenic shock } \\
\text { Sepsis`} \\
\text { Haemorrhagic shock or hypovolaemia } \\
\text { After cardiac arrest } \\
\text { Gastrointestinal } \\
\text { Bleeding } \\
\text { Haematological } \\
\text { Renal } \\
\text { Metabolic } \\
\text { Diabetic ketoacidosis } \\
\text { Neurological } \\
\text { Head trauma } \\
\text { Drug overdose } \\
\text { Intracerebral, subdural, or subarachnoid } \\
\text { haemorrhage } \\
\text { Seizure disorder } \\
\text { Respiratory } \\
\text { Infection } \\
\text { Neoplasm } \\
\text { Pulmonary embolus } \\
\text { Non-cardiogenic lung oedema } \\
\text { After respiratory arrest } \\
\text { Asthma or allergy } \\
\text { Chronic obstructive lung disease } \\
\text { Aspiration, poisoning, or toxic }\end{array}$ & $\begin{array}{r}0.470 \\
-1.228 \\
-0.191 \\
0.731 \\
-0.424 \\
-1.798 \\
-1.368 \\
-0.259 \\
0.113 \\
0.493 \\
0.393 \\
0.501 \\
0.334 \\
-0.885 \\
-0.885 \\
-0.885 \\
-1.507 \\
-0.759 \\
-0.517 \\
-3.353 \\
\\
0.723 \\
-0.584 \\
-0.890 \\
0 \\
0.891 \\
-0.128 \\
-0.251 \\
-0.168 \\
-2.108 \\
-0.367 \\
-0.142\end{array}$ \\
\hline
\end{tabular}

^If surgical patient use non-surgical coefficient.

predicted risk of dying in hospital estimated by the APACHE II equation. Risks from $0 \%$ to $100 \%$ were grouped in intervals of $5 \%$. The observed proportion of deaths within each risk group and its $95 \%$ confidence interval were plotted and compared with the diagonal line that represented the relation where observed and predicted death rates were equal (perfect predictive ability).

Classification tables constructed for predictive models compare observed with predicted outcomes. Individual predicted risks were converted to predicted outcomes with different decision criteria. For example, with a decision criterion of $50 \%$ probability predicted risks of dying greater than $50 \%$ were considered to predict hospital mortality and predicted risks of $50 \%$ or less to predict survival. These predicted outcomes were then compared with the observed outcomes. Similarly, a decision criterion of $25 \%, 75 \%$, or any other value can be used. The true positive rate or sensitivity (the proportion of the observed non-survivors who were correctly predicted to die); the false positive rate or $100 \%$ minus the specificity (the proportion of observed survivors incorrectly predicted to die); and the overall correct classification rate (proportion of patients correctly classified as survivors or non-survivors) can be compared for different predictive models applying different decision criteria.

Receiver operating characteristic curves show the relation between the true positive rate (sensitivity) and the false positive rate $(100 \%$ minus the specificity) as the decision criterion for prediction is systematically varied from 0 to $100 \%$. They therefore depict the trade offs between the true positive rate and the false positive rate for a given predictive model. The total area under a curve is an expression of the overall discrimination across the range of risks and is a good summary measure of predictive ability. It has a minimum value of 0.5 represented by a diagonal line, which would be expected if the model was no better than chance at predicting hospital mortality. It has a maximum value of 1.0 represented by a line superimposed on the $y$ axis from the origin to the upper left hand corner of the graph for perfect prediction. The value of the area under the curve represents the likelihood that a non-survivor randomly chosen from the database will have a greater predicted probability of dying in hospital than a randomly chosen survivor. The true positive rates and false positive rates were calculated from the classification tables using decision criteria ranging from 0 to $100 \%$ in $5 \%$ intervals. Receiver operating characteristic curves were constructed by plotting the false positive rate along the $\mathrm{x}$ axis against the true positive rate on the $\mathrm{y}$ axis for each decision criterion.

Lemeshow-Hosmer $\chi^{2}$ statistic-As for the calibration curve, observations were divided into mortality risk groups on the basis of their predicted risk of dying in hospital. The groups ranged from 0 to $100 \%$ in $10 \%$ intervals. Both the observed number of survivors and non-survivors and the predicted number of survivors and non-survivors were calculated for each risk group. The $\chi^{2}$ statistic comparing the observed with the expected (predicted) frequencies was calculated for each of the 10 groups for both survivors and non-survivors. The 20 $\chi^{2}$ values were summed and the resultant Lemeshow-Hosmer statistic had a distribution that was closely approximated by a $X^{2}$ distribution, with the number of degrees of freedom equal to the number of risk groups minus two, when observed mortality is accurately predicted across the range of risk (this is the null hypothesis). For a given sample size the overall $\chi^{2}$ values are therefore smaller the better the goodness of fit. A high (and significant) $\chi^{2}$ value can, however, be achieved with increasing sample sizes despite an excellent fit as the power for detecting departures from the null hypothesis increases.

1 Knaus WA, Draper EA, Wagner DP, Zimmerman JE. APACHE II: a severity of disease classification system. Crit Care Med 1985;13:818-29.

2 Knaus WA, Draper EA, Wagner DP, Zimmerman JE. An evaluation of outcome from intensive care in major medical centers. Ann Intern Med 1986;104:410-8.

3 Wagner DP, Knaus WA, Draper EA. The case for adjusting hospital death rates for severity of illness. Health Aff (Millwood) 1986;5:149-53.

4 Zimmerman JE, Knaus WA, Judson JA, Havill JH, Trubuhovich RV, Draper EA, et al. Patient selection for intensive care: a comparison of New Zealand EA, et al. Patient selection for intensive care: a comparison

5 Sirio CA, Tajimi K, Tase C, Knaus WA, Wagner DP, Hirasawa H, et al. An initial comparison of intensive care in Japan and the United States. Crit Care Med 1992;20:1207-15.

6 Chisakuta AM, Alexander JP. Audit in intensive care. The APACHE II classification of severity of disease. Ulster Med $\mathcal{F}$ 1990;59:161-7.

7 Turner JS, Mudaliar YM, Chang RWS, Morgan CJ. Acute physiology and chronic health evaluation (APACHE II) scoring in a cardiothoracic intensive care unit. Crit Care Med 1991;19:1266-9.

8 Turner JS, Potgieter PD, Linton DM. Severity of disease classification system. Crit Care Med 1991;19:301-2.

9 Marsh HM, Krishan I, Naessens JM, Strickland RA, Gracey DR, Campion $\mathrm{ME}$, et al. Assessment of prediction of mortality by using the APACHE II ME, et al. Assessment of prediction of mortality by using the APACHE
scoring system in intensive care units. Mayo Clinic Proc 1990;65:1549-57.

10 Rowan KM, Kerr JH, Major E, McPherson K, Short A, Vessey MP. Intensive Care Society's APACHE II study in Britain and Ireland. I. Variations in case mix of adult admissions to general intensive care units and impact on outcome. BMF 1993;307:972-7.

11 Gardner MJ, Altman DG. Statistics with confidence. London: British Medical Journal, 1989.

12 Hanley JA, McNeil BJ. The meaning and use of the area under a receiver operating characteristic (ROC) curve. Radiology 1982;143:29-36.

13 Lemeshow S, Hosmer DW. A review of goodness of fit statistics for use in the development of logistic regression models. Am $f$ Epidemiol 1982;115: 92-106.

14 Daley J, Jencks S, Draper D, Lenhart G, Thomas N, Walker J. Predicting hospital-associated mortality for Medicare patients. $\exists A M A$ 1988;260: 3617-24.

15 Agarwal N, Sankari M, Cayten CG, Brown BB, Murphy J, Byrne D, et al. Influence of age on mortality of surgical intensive care unit (SICU) patients. Crit Care Med 1989;17:S85.

16 Payer L. Medicine and culture. London: Gollancz, 1989:15-22.

(Accepted 17 August 1993) 